\title{
Chemistry Nobel won by ... chemists
}

\section{Synthesis method scoops prize for first time in five years.}

\section{BY RICHARD VAN NOORDEN}

$\mathrm{F}$ Ior three of the past four years, the committee that awards the Nobel Prize in Chemistry has scattered its medals in biological fields (see 'Biology's decade'), prompting inevitable and often fruitless introspection from chemists about their field's identity. So this year's award has been welcomed as a return to what many see as chemistry's core, almost monastic, discipline: synthesizing molecules.

Richard Heck, Ei-ichi Negishi and Akira Suzuki won for their development of reactions that stitch together molecules by cleanly connecting chains of carbon atoms, using small amounts of catalysts based on the metal palladium. The processes they uncovered for forming carbon-carbon bonds in the 1960s and 1970s are now a staple of chemistry textbooks, and are

\section{BIOLOGY'S DECADE}

Since 2001, the chemistry Nobel has been awarded in biological $\bar{\delta}$ areas more often than for synthesis $\mathbf{A}$, physical or analytical $\mathbf{0}$ work

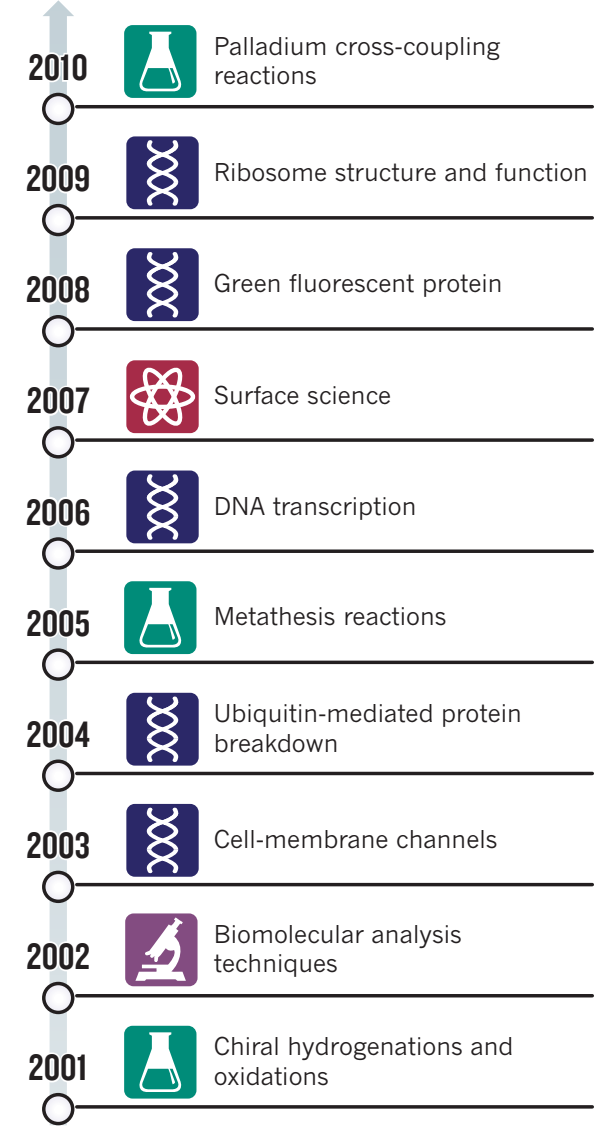

used every day in industry and academia.

Chemists hoping to connect carbon chains once faced an arduous task. Reaction mixtures often produced a mess of by-products that would form a sludge at the bottom of a chemist's reaction flask. But by 1968 , Heck — then at Hercules, a chemical company in Wilmington, Delaware, and later at the University of Delaware in Newark - had found that palladium combines with organic molecules to produce a catalyst that dramatically improves such tricky couplings. The palladium atom inserts itself between atoms in the carbon-carbon chains as the reaction proceeds, effectively guiding molecules towards the desired product with few messy side reactions. In the late 1970s, Negishi, of Purdue University in West Lafayette, Indiana, and Suzuki, at Hokkaido University in Sapporo, Japan, published their own variations on this theme, each using different palladium-based catalysts.

The palladium couplings didn't just ease the process of synthesizing compounds; they prompted molecule-makers to experiment with new classes of drugs, and with materials that were previously too hard to make. It took a decade before the processes caught on with industrial chemists, says Andrew Wells, a chemist at multinational drug giant AstraZeneca in Loughborough, UK, but about $15-30 \%$ of compounds in development at his company now rely on palladium-catalysed cross-coupling reactions. The anti-cancer drug Gleevec (imatinib) and the blood-pressure medication Diovan (valsartan), as well as the fungicide boscalid, are just some of the fruits of palladium chemistry.

Many chemists say they are delighted by the recognition of work at the heart of their discipline. "There's an extent to which chemistry is buggered at both ends," comments Eric Scerri, a philosopher of chemistry at the University of California, Los Angeles. "Physicists say it's nothing but physics. At the other end it's being encroached on by biologists who see it as just a tool for biology."

Roald Hoffmann of Cornell University in Ithaca, New York, who won the 1981 Nobel Prize in Chemistry, sees no point in complaining about the Nobel committee's biological bent. "The Nobel committee has decided that molecular biology and biochemistry are chemistry, no matter what chemists think," he says. "I don't think it's quite right, but I don't feel too bad about it." - 